\section{Estudo cobebate}

em Cestão Planejamento
Revista Estudo \& Debate, Lajeado, v. 24, n. 3, 2017. ISSN 1983-036X

DOI: http://dx.doi.org/10.22410/issn.1983-036X.v24i3a2017.1438

\title{
INDISCIPLINA E VIOLÊNCIA ESCOLAR: UMA ANÁLISE DAS ESCOLAS PÚBLICAS DO RIO GRANDE DO SUL
}

\author{
Maicker Leite Bartz ${ }^{1}$, Ewerton da Silva Quartieri² ${ }^{2}$ Tiarajú Alves de Freitas ${ }^{3}$
}

\begin{abstract}
Resumo: No Brasil ainda são poucos os trabalhos empíricos que tratam de indisciplina e violência escolar, o que dificulta a identificação de padrões por parte de gestores e tomadores de políticas públicas na hora de controlar tais ocorrências nas escolas. Visando ajudar a preencher essa lacuna, o presente artigo utilizará uma base de dados bem recente e ainda pouco utilizada, onde estão presentes informaçôes de diversas ocorrências nas escolas estaduais do Rio Grande do Sul. A partir dessas informaçôes, foram criados indicadores que pretendem classificar as escolas maior incidência desses atos no Estado. Dos diversos dados presentes, optou-se por trabalhar com indicadores de agressão entre alunos, agressão a professores, bullying e indisciplina escolar. Os resultados apontaram que a maioria das escolas presentes nos rankings de escolas com maior incidência de violência e indisciplina, estáo presentes na Regiâo Metropolitana de Porto Alegre. Isso pode estar, de certa forma, relacionado aos maiores índices de violência urbana que os municípios apresentam, influenciando o comportamento dos alunos nas escolas. No entanto, muitas escolas apresentaram zero casos, demonstrando que, mesmo que muitas escolas desses municípios mais violentos sofram influência da violência urbana, outras conseguem minimizar a situaçáo de violência, talvez por fatores propriamente internos da escola, como a infraestrutura, a gestão, a qualidade dos professores, dentre outros.
\end{abstract}

Palavras-chave: Indicadores sociais. Violência escolar. Indisciplina. Rio Grande do Sul.

1 Possui graduaçáo em Ciências Econômicas pela Universidade Federal do Rio Grande (2015). Atualmente é mestrando em Economia Aplicada pela Universidade Federal do Rio Grande. Tem experiência nas áreas de mercado de trabalho e economia do crime.

2 Possui ensino médio pela ENCCEJA(2008). Tem experiência na área de Economia.

3 Possui doutorado em Economia Aplicada pelo PPGE da Universidade Federal do Rio Grande do Sul (2010). É professor e pesquisador do Programa de Pós-Graduação em Economia do Mar - FURG. Possui graduação em Ciências Econômicas pela Universidade Federal do Rio Grande (1999) e mestrado em Economia pela Universidade Federal do Ceará (2001). Atualmente é professor adjunto três da Universidade Federal do Rio Grande. Tem experiência na área de Economia, com ênfase em Microeconomia e Teoria dos Jogos, atuando principalmente nos seguintes temas: assimetria de informação, defesa da concorrência, dispersão de preços, economia da regulação e indicadores econômicos. É coordenador do Centro Integrado de Pesquisas da FURG e coordenador do curso de Ciências Econômicas da FURG. 


\title{
INDISCIPLINE AND SCHOOL VIOLENCE: AN ANALYSIS OF RIO GRANDE DO SUL PUBLIC SCHOOLS
}

\begin{abstract}
In Brazil, there are still few empirical studies that talk about indiscipline and school violence, which makes it difficult for policy makers to identify patterns when it comes to controlling violence in schools. In order to help fill this gap, this article will use a quite recent and still not very popular database, in which the informations about various violent acts in the state schools of Rio Grande do Sul are presented. From these informations, indicators that intend to classify the most violent schools in the state were created. From the numerous data presented, indicators of aggression among students, aggression against teachers, bullying and school indiscipline were chosen to work with. The results showed that most of the places that appearedin the ranking of most violent schools are located in the Metropolitan Region of Porto Alegre. This may be, to a certain extent, related to the higher rates of urban violence that such cities present, influencing the violent behavior of students in the institutes they study. However, many schools presented zero cases of violence, demonstrating that even though many of the places in these more violent towns are influenced by urban violence, others are able to minimize violent acts. This may be due to school internal factors such as infrastructure, management, quality of teachers, among others.
\end{abstract}

Keywords: Social indicators. School violence. Indiscipline. Rio Grande do Sul.

\section{INTRODUÇÃO}

Uma variável fundamental na determinação do progresso econômico de qualquer nação é a educação. Nesse seguimento, quanto maior o nível educacional dos indivíduos, maiores os níveis de capital humano e taxas de crescimento econômico. Nesse sentido alguns autores relatam que a violência escolar pode ser um fator que acabe gerando problemas tanto na qualidade do ensino, quanto na aprendizagem dos alunos (ABRAMOVAY; RUA, 2002). Teixeira e Kassouf (2015) seguem essa mesma ideia, afirmando que tal problema, dadas as proporçóes, pode diminuir o nível de capital humano - fator determinante do desenvolvimento humano.

O modo como a violência escolar é analisada sofreu algumas mudanças ao longo do tempo. Anteriormente a violência no meio escolar era vista por meio de puniçóes e castigos de professores contra alunos. Atualmente, conforme citado por Abramovay e Rua (2002), sociólogos, psicólogos, antropólogos, dentre outros especialistas, voltam seus estudos bem mais para violência entre alunos ou atos cometidos por alunos contra a escola. Isso pode ser visto no trabalho dos autores, onde os mesmos analisaram diversas escolas de capitais do Brasil. Estes pesquisadores concluíram que a violência por parte dos alunos é predominante dentre os diversos tipos de violência dentro da escola.

Alguns autores relatam que um comportamento agressivo e violento de um jovem na escola pode, em alguns casos, influenciar no desenvolvimento criminoso na sua vida adulta. É importante salientar que um comportamento violento de um jovem dentro da escola não o tornará um delinquente, porém, a probabilidade de um delinquente manifestar comportamento violento desde a escola é alta (BECKER; KASSOUF, 2016). Sobre este assunto, destaca-se o trabalho de Farrington (1990) apud Becker e Kassouf (2016), que analisou o comportamento agressivo manifestado na infância de homens com 32 anos. Os resultados apontaram que dos indivíduos que não apresentaram comportamento agressivo 
na infância, $31 \%$ foi condenado por algum tipo de crime, já para quem detinha um comportamento agressivo desde a infância, o resultado foi de 57\%.

Visto algumas das consequências que a violência escolar pode trazer para a sociedade, o presente estudo visa contribuir para a literatura de violência escolar, a partir do estudo de uma base de dados ainda pouco explorada que trata de ocorrências de diversos atos de violência e indisciplina nas escolas estaduais do Rio Grande do Sul. Esse é um primeiro estudo sobre esses dados, onde se pretende analisar quais são as escolas estaduais mais violentas e indisciplinadas do estado. Para isso serão criados alguns indicadores que vão tratar especificamente de violência entre alunos, violência contra os professores, bullying e indisciplina escolar. A amostra analisada será de 1333 escolas estaduais do Rio Grande do Sul, e a metodologia será uma adaptação de Freitas, Cadaval e Gonçalves (2015).

Além dessa introdução, o trabalho está dividido em mais 4 seções: (i) referencial teórico, onde são apresentados os principais trabalhos do tema; (ii) metodologia, que explicará o método utilizado para identificar as escolas mais violentas; (iii) resultados, que apresentará os indicadores de cada tipo de ocorrência analisada e; (iv) consideraçóes finais, onde apresenta-se o resumo dos principais resultados e indicaçóes de possíveis trabalhos futuros.

\section{REFERENCIAL TEÓRICO}

A violência escolar, por incumbir sérias consequências dentro da sociedade, acaba sendo um assunto que desperta interesse de autoridades, no entanto, não existem muitas pesquisas empíricas que tratem do tema. Sposito (1998) relata que foram defendidos 6.092 trabalhos de dissertação de mestrado e tese de doutorado no Brasil no período de 1980 e 1995 e destes, apenas 4 trabalhos referiam-se à violência escolar. Teixeira e Kassouf (2015) argumentam que a maioria dos trabalhos desse tema foram realizados nos últimos anos, onde são analisados, principalmente, os impactos de violência dentro e fora da escola.

Martins, Machado e Furlanetto (2016) sugerem que os conflitos que acarretam em violência, no âmbito escolar, são influenciados por causas externas e internas. Dentre os fatores externos estão as condiçóes socioeconômicas e culturais, que englobam situaçóes de famílias expostas a violências nas comunidades; influência dos grupos de referências, tais como os amigos; preconceitos religiosos e étnico-raciais; prática de bullying. Com o intuito de combater essas adversidades, as características internas das escolas têm papel fundamental. É necessário, sobretudo, que gestores, professores e funcionários compreendam a dimensão dos problemas trazidos pelos alunos, construindo um ambiente coletivo de apoio para evitar/superar sentimentos de marginalização e insegurança no espaço escolar (MARTINS; MACHADO; FURLANETTO, 2016).

Um primeiro trabalho relevante sobre o tema em questáo foi o de Grogger (1997), onde o autor analisou as consequências da violência escolar sobre o desempenho de alunos nos Estados Unidos. Os resultados apontaram que níveis moderados de violência refletem tanto na dificuldade de conclusão do ensino médio, quanto na frequência escolar. Nesse sentido, na literatura internacional, existe uma gama de trabalhos que chegam nessa mesma conclusão: violência escolar afeta o desempenho dos alunos. Isso pode ser conferido 
em Henrich et al. (2004), Ratner et al. (2006), McGarvey et al (2006), Carroll (2006), Ammermueller (2007).

No Brasil, a maioria dos trabalhos empíricos de avaliação de violência escolar utilizam a Prova Brasil como base de dados. A maioria dos trabalhos que a utilizam avaliam os efeitos da violência sobre o aprendizado e o comportamento dos jovens. Autores como Gama (2009) verificam que o desempenho escolar é afetado negativamente pelas ocorrências de violência. Severnini e Firpo (2009) também chegam a mesma conclusão, assim como Oliveira e Ferreira (2013).

Ainda no Brasil, destacam-se os recentes trabalhos de Becker e Kassouf (2016) e Tavares e Pietrobom (2016), que abordam a violência escolar de uma maneira diferente. $\mathrm{O}$ primeiro trabalho avalia se o ambiente onde os jovens estão inseridos influenciam ou não no comportamento agressivo dos mesmos. Para isso, as autoras utilizaram um modelo logit com variáveis referentes a fatores econômicos e sociais da escola, do comportamento dos professores, dos pais, entre outros. As conclusóes foram que o meio onde o jovem está inserido impacta no seu comportamento violento. Nesse caso, os resultados apontaram para uma probabilidade maior de um jovem cometer uma agressáo se ele estiver inserido em uma escola onde ocorrem crimes contra pessoa, crimes contra o patrimônio, atuação de gangues, tráfico de drogas, entre outros. Além disso, as autoras inferiram que, em escolas onde professores cometeram algum tipo de agressão contra algum professor ou funcionário, a probabilidade de um aluno cometer alguma agressáo a qualquer membro da escola (aluno, funcionário, professor), é 3,54 vezes maior.

Já o trabalho da Tavares e Pietrobom (2016) utiliza uma base de dados inédita referente a ocorrências de atos violentos nas escolas estaduais de São Paulo. O trabalho visa investigar os fatores associados com a violência dentro das escolas, por meio de $s$ características internas das escolas e do seu entorno, dos diretores, dos professores, dos alunos e da família. Os resultados apontaram que os delitos cometidos por agentes externos à escola estão associados às condições socioeconômicas do entorno das escolas e da gestão escolar. Já as causas dos atos violentos relacionadas aos agentes internos estão relacionados a composição social e demográfica do corpo discente, além do seu background familiar ${ }^{4}$.

Em relação a trabalhos que tratem especificamente de violência contra o professor, cita-se, inicialmente, o de Rocha et al (2012). A pesquisa dos autores leva em consideração 121 professores de escolas particulares e públicas em Natal, Rio Grande do Norte. Com essa amostra, as autoras buscam evidenciar as características dos professores e se eles já sofreram algum tipo de violência dentro da escola. Os resultados apontaram que, dos 121 professores entrevistados, 37 já tinham sofrido algum tipo de agressão por parte dos alunos. Destas, $58 \%$ correspondeu a agressão verbal, $18 \%$ a violência indireta, $13 \%$ a violência psicológica e $11 \%$ agressão física.

4 Basicamente refere-se ao ambiente familiar do jovem, tal como os níveis educacionais dos pais, as experiências profissionais, o nível cultural, etc. 
Uma pesquisa da Organização para a Cooperação e Desenvolvimento Econômico $(\mathrm{OCDE})^{5}$ classificou o Brasil como o país com o maior índice de violência contra os professores. Segundo a pesquisa, $12,5 \%$ dos professores ouvidos no Brasil disseram que foram vítimas de agressóes verbais ou de intimidação de alunos uma vez por semana pelo menos. Dentre os 34 países pesquisados, esse foi o pior índice, sendo a média de todos os outros países de 3,4\%. Coréia do Sul, Malásia e Romênia foram os exemplos positivos, apresentando índice zero. Um outro fator pesquisado que pode justificar essa alta violência relatada nas escolas brasileiras, é o fato que no Brasil apenas 12,6\% dos professores acreditam que a profissão é valorizada, enquanto que a média global é de 31\%. O Brasil está entre os dez últimos colocados nesse quesito, enquanto Malásia, Cingapura e Coréia do Sul, em contraste, estâo nas primeiras posiçôes, e possuem os menores índices de violência contra o professor. A pesquisa ainda abrange os rendimentos dos professores. Sobre esse quesito, o Brasil apresenta um salário médio de $\mathrm{R} \$ 1,9$ mil por mês, já os países pertencentes a OCDE, possuem uma média de salário de $\mathrm{R} \$ 5,7$ mil por mês, representando o triplo do que é pago no Brasil.

Um outro ponto que deve ser analisado é o bullying. No Brasil, no ano de 2009, a Pesquisa Nacional de Saúde do Escolar (PeNSE) concluiu que 30,8\% dos alunos já tinham sofrido bullying alguma vez (IBGE, 2009). Diversos estudos demonstram que a violência, bem como o bullying, trazem algumas consequências para os agressores e as vítimas. Isso pode ser consultado em Silva et al (2016), onde os autores fizeram uma revisão de estudos que tratam de bullying escolar e conduta infracional na adolescência e na idade adulta. Os autores levantaram no total 13 artigos nesse tema e concluíram, dada essa revisão literária, que os indivíduos que cometem bullying na juventude tem maior probabilidade de entrar para o crime.

Nessa mesma perspectiva, Olweus (2011) verificou que há conexão entre bullying na adolescência e criminalidade adulta. Os resultados do autor apontaram que agressores que praticavam bullying na adolescência, quando comparado com os que não detinham esse comportamento, possuíam uma probabilidade maior de 5 vezes de condenação. Tem-se ainda os trabalhos de Renda et al. (2011), que encontrou uma relação positiva entre bullying com o fato de ter passagens pelo Sistema de Justiça, e o trabalho de Piquero et al. (2013), que associou positivamente o bullying com algumas trajetórias infracionais.

Em relação a indisciplina escolar, Silva e Nogueira (2008) falam que a mesma está associada aos comportamentos menos graves que violam regras puramente escolares, não trazendo danos instantâneos às pessoas. Os autores citam como exemplos de indisciplina escolar: chegar atrasado; brincadeiras incomodas; conversas clandestinas dentro da sala de aula; desobedecer às ordens dos professores; réplicas às açōes disciplinadoras dos docentes. Nesse sentido, a medida que essas ocorrências se tornam muito constantes, os comportamentos de indisciplina acarretam maior gravidade, apresentando grande poder perturbador da relação pedagógica e impedimento de um bom andamento das aulas

5 Para saber mais ver: http://www.bbc.com/portuguese/noticias/2014/08/140822_salasocial_eleicoes_ocde_ valorizacao_professores_brasil_daniela_rw 
(SILVA; NOGUEIRA, 2008). Isso pode ocasionar um impacto significativo sobre o clima escolar, a socialização e a aprendizagem dos estudantes (CAMACHO, 2001 apud MATOS; FERRÃO, 2016).

\section{MÉTODO E DADOS}

Neste trabalho foram utilizados dados divulgados pela Comissão Interna de Prevenção a Acidentes e Violência Escolar (CIPAVE $\backslash$ RS), que é um programa desenvolvido pela Secretária de Educação do Rio Grande do Sul que visa orientar a comunidade escolar sobre as mais diversas situaçóes que podem ocorrer no ambiente escolar, a partir de informaçóes sobre ocorrências de indisciplina, agressóes, depredaçóes, atos de bullying, entre outros. A Secretária de Educação do Rio Grande do Sul, em conjunto com as CIPAVE's, ainda distribui, nas escolas públicas do estado, cartilhas que contém informaçóes sobre as condutas que as crianças devem tomar, além de informações sobre o que é indisciplina, bullying, e as consequências dessas açóes. Como o presente trabalho irá utilizar diferentes conceitos, é necessário detalhar algum deles para melhor entendimento. De acordo com a CIPAVE, os atos de indisciplina escolar são atitudes de crianças e adolescentes que estão em desacordo com o regimento da escola, praticados de forma contrária às normas de convivência do estabelecimento de ensino. Já o bullying, caracterizado de acordo com o Art. 2o da Lei $n^{\circ} 13.185 / 2015$, é “quando há violência física ou psicológica em atos de intimidação, humilhação ou discriminação e, ainda: ataques físicos, insultos pessoais, comentários sistemáticos e apelidos pejorativos, ameaças por quaisquer meios, grafites depreciativos, expressóes preconceituosas, isolamento social consciente e premeditado e pilhérias.

Outro tipo de ocorrência que pode ocorrer na escola é a violência física entra os alunos, a qual trata especificamente do ambiente hostil de agressão física entre os alunos nas escolas. Por fim, a violência contra o professor - que inclui também violência contra funcionários e ao diretor - trata tanto de agressão verbal como agressão física cometida por alunos.

É preciso deixar claro que alguns desses atos envolvem algumas características comuns como, por exemplo, a violência física e o bullying, portanto, pretende-se fazer uma análise para cada tipo de conduta violenta, visto que o bullying abrange outras condutas além da agressão física.

As informações da amostra de dados compreendiam inúmeras informações sobre violência escolar, no segundo semestre de 2016, em 1.796 escolas estaduais do Rio Grande do Sul. Este valor representa aproximadamente $70 \%$ do total de escolas estaduais do Rio Grande do Sul. No entanto, o presente artigo irá trabalhar com uma amostra de 1.333 escolas, tendo em vista que algumas escolas possuíam menos de 100 alunos e, os indicadores que foram calculados, utilizam a ocorrência de determinado ato pelo total de alunos da escola. Por isso, para facilitar a análise, não se utilizou essas escolas com menos de 100 estudantes. Em relação aos indicadores, será utilizada a mesma metodologia de Freitas, Cadaval e Gonçalves (2015), onde foi desenvolvido um Indicador Geral de Criminalidade (IGCrime) para os municípios do Rio Grande do Sul. Assim, para esse artigo, serão criados indicadores escolares para indisciplina, agressão entre alunos, agressão contra professores 
e bullying. Com essas informaçôes, mais o total de alunos de cada escola, calculou-se os indicadores para cada 100 estudantes. A fórmula utilizada pode ser vista abaixo:

$$
T O_{j i}=\frac{\text { ocorrências }_{j i} \times 100}{\text { alunos }_{i}}
$$

Onde:

$$
i=1,2, \ldots, 1.333 ; j=1,2,3,4 \text {; }
$$

$T O_{j i}$ é a taxa de ocorrência para cada 100 alunos.

Em vista que ainda náo haviam sido disponibilizados os dados do Censo escolar do ano de 2016, as informaçóes do total de alunos de cada escola são provenientes do Censo Escolar de 2015. Essa estratégia foi adotada em vista que a CIPAVE dispóe o total de alunos em forma de intervalo, como por exemplo, de 200 a 500 alunos, o que impossibilitaria o cálculo das taxas de ocorrência. Acredita-se que não haveria tanta mudança no número de alunos. Um fator que comprova isso é que, ao analisar as informaçóes dos dados do total de alunos do Censo, com o intervalo de dados da CIPAVE, todas escolas que estão presentes nos rankings dos resultados ficaram dentro do intervalo. Dentre as outras escolas, a maioria ficou dentro desses intervalos também. Na tabela abaixo é apresentada a evolução das taxas de matrículas do Rio Grande do Sul entre 2000 e 2015. Pode-se perceber que desde 2010 há uma queda média de 3\% nas matrículas das escolas estaduais. Uma possível estratégia a ser aplicada, seria aplicar esse percentual sobre o total de alunos de cada escola, mas por aplicarmos em todas as escolas, o resultado se manteria o mesmo.

Tabela 1 - Evoluçấo do total de alunos das escolas estaduais do Rio Grande do Sul

\begin{tabular}{c|c|c}
\hline Ano & Total de alunos & Percentual \\
\hline 2010 & 1.158 .483 & \\
\hline 2011 & 1.118 .319 & $-3,59 \%$ \\
\hline 2012 & 1.083 .873 & $-3,18 \%$ \\
\hline 2013 & 1.050 .692 & $-3,16 \%$ \\
\hline 2014 & 1.013 .582 & $-3,66 \%$ \\
\hline 2015 & 973.020 & $-4,17 \%$ \\
\hline
\end{tabular}

Fonte: Elaboração própria com base nos dados da Secretária de Educação RS.

A tabela a seguir mostra o percentual de ocorrências das escolas com mais de 500 estudantes. Pode-se perceber que 411 escolas, de 1.333 presentes na amostra, apresentam mais de 500 alunos, indicando uma maior concentração de escolas com menos de 500 estudantes. No entanto, por mais que $69 \%$ das escolas, presentes na amostra, possuírem menos de 500 estudantes, a proporção de ocorrências é de apenas 55\%, enquanto que as escolas maiores, $31 \%$ da amostra, apresentam $45 \%$ das ocorrências. 
Tabela 2 - Ocorrências para as maiores escolas estaduais do Rio Grande do Sul

\begin{tabular}{l|l|l|l}
\hline & Total(A) & Total (B) & $(\mathrm{A}) /(\mathrm{B})$ \\
\hline Quantidade de escolas & 411 & 1.333 & $31 \%$ \\
\hline Indisciplina & 11.184 & 24.466 & $46 \%$ \\
\hline Violência entre alunos & 2.658 & 6.314 & $42 \%$ \\
\hline Violência contra o professor & 2.927 & 6.870 & $43 \%$ \\
\hline Bullying & 2.704 & 5.225 & $52 \%$ \\
\hline Total ocorrências & 19.473 & 42.875 & $45 \%$ \\
\hline
\end{tabular}

$(\mathrm{A})=411$ escolas com mais de 500 estudantes; $(\mathrm{B})=1.333$, total de escolas

Fonte: elaboração própria.

Embora as grandes escolas concentrem uma parcela significativa do total de ocorrências praticadas nas escolas estaduais do estado, a ocorrência de cada evento impacta de forma diferente sobre os índices de escolas de portes diferentes. A proporção representada pela ocorrência de um ato violento/100 estudantes é substancialmente diferente entre escolas grandes e pequenas. Neste sentido, a ocorrência aleatória de um ato violento em uma escola com pequena quantidade de alunos tem grande impacto, podendo gerar a informação de que determinado índice, em determinada escola, em dado município, é elevado, em dado período, justificando uma possível aplicaçáo de recursos na área. No entanto, se o evento não se repete ao longo do tempo, não haveria necessidade de mobilizar tais recursos, uma vez que o evento é aleatório.

Com o intuito de se retirar a hipótese de aleatoriedade sobre as estimativas de ocorrências escolares, aplicou-se uma taxa bayesiana para o grupo dos 1.333 municípios. Buscou-se, assim, incorporar os riscos contidos em outras áreas, neste caso escolas de mesmo tamanho, para estimar o risco de uma escola específica.

O método proposto por Marshall (1991), visto em Freitas, Cadaval e Gonçalves (2015), foi utilizado aqui e consiste em calcular uma taxa de risco ponderada por dois elementos, um contendo o evento ocorrido, ponderado por uma constante c entre zero e um e, somado a outro elemento cuja constante é o complementar de c multiplicado pela taxa média dos eventos ocorridos em escolas de mesmo porte. Em termos de equação, a taxa de risco de uma escola segue a seguinte regra:

$$
T O b_{j i}=c \times T O_{j i}+(1-c) \times T O m_{j}
$$

Onde:

$i=1,2, \ldots 1.333 ; j=1,2,3,4$

$\mathrm{TOb}_{j i}$ é a estimativa corrigida do total de ocorrências registradas;

$c$ é o parâmetro que amortece o valor do evento ocorrido na escola quando o número de estudantes é pequeno;

$T O_{j i}$ é o evento ocorrido na escola; 
$T O m_{j k}$ é a taxa média da classe obtida entre escolas com número de estudantes semelhante.

As classes escolhidas foram de acordo com o proposto por Freitas, Cadaval e Gonçalves (2015), seguindo a disposição dos dados que estavam em intervalor de classe. Dessa forma, as classes foram separadas por esse princípio: a classe que recebeu c igual a 1 foi a classe que tinha maior média de alunos e que estava no intervalo de mais de 1000 estudantes, o restante foi distribuído de acordo com a tabela a seguir.

Tabela 3 - Caracterização do valor atribuído ao grau de aleatoriedade através do coeficiente c

\begin{tabular}{c|l|l|r|c}
\hline Classe & Faixa de estudantes & $\mathrm{n}^{\mathrm{o}}$ escolas & Média alunos(A) & $\mathrm{C}(\mathrm{A} \backslash \mathrm{B})$ \\
\hline 1 & 50 a 200 & 324 & 155,12 & 0,13 \\
\hline 2 & 200 a 500 & 598 & 333,83 & 0,28 \\
\hline 3 & 500 a 1000 & 303 & 708,66 & 0,60 \\
\hline 4 & mais de 1000 & 108 & $\mathrm{~B}=1167,76$ & 1,00 \\
\hline
\end{tabular}

Fonte: elaboração própria.

Assim, o valor atribuído a cada coeficiente de ajuste, para cada faixa de estudantes, é gerado pela proporção da média de alunos de cada faixa em relação à média de alunos da faixa de estudantes com mais alunos.

Depois de todos esses procedimentos pode-se, por fim, calcular os indicadores propostos. Com a informação da taxa de ocorrência bayesiana de cada ato, para cada escola, o próximo passo é identificar as taxas mínimas e máximas de atos ocorridos para cada um dos quatro indicadores. Estas taxas serão parâmetros entre os limites inferiores e superiores de referência para as amplitudes mínimas e máximas que poderão apresentar. Subtrai-se a ocorrência da escola da ocorrência mínima entre todas as escolas. Posteriormente, se divide o resultado pela diferença entre os parâmetros máximo e mínimo. Os índices terão valores entre zero e um, isso significa que, as escolas que possuírem valores próximo a 1 , serão classificadas como as escolas que detinham maior incidência de violência escolar e indisciplina no período analisado. De forma algébrica tem-se:

$$
\text { Índice } e_{j i}=\frac{\left(T O b_{j i}-T O b_{j \min }\right)}{\left(T O b_{j \operatorname{má} x}-T O b_{j \min }\right)}
$$

Onde:

$i=1,2, \ldots 1.333 ; j=1,2,3,4$;

Índice $_{j i}$ é o índice da ocorrência $j$ ocorrido na escola;

$T O b_{j i}$ é a estimativa corrigida do total de ocorrências registradas;

$T O b_{j \text { min }}$ é o menor valor registrado no período analisado para a taxa de ocorrência $j$;

$T O b_{\text {jmáx }}$ é o maior valor registrado no período analisado para a taxa de ocorrência $j$. 
Por fim, o intervalo entre zero e um, de abrangência de cada um dos quatro indicadores aqui trabalhados - indisciplina, bullying, violência entre alunos, violência contra o professor, funcionário e diretor - será dividido em quatro faixas. A primeira, entre zero e 0,1 , denominada como pouco frequente. A segunda, maior que 0,1 até 0,3 , considerada como frequente. A terceira, maior que 0,3 até 0,5 , definida como muito frequente. Por fim, a última faixa, extrema frequência, com valores maiores que 0,5 até 1 .

\section{RESULTADOS}

Nesse tópico serão demonstradas algumas estatísticas descritivas dos dados e os resultados dos indicadores das escolas com maior incidência de atos violentos e indisciplinares do Rio Grande do Sul.

\subsection{Estatística descritiva dos dados}

No gráfico abaixo temos as ocorrências totais de indisciplina e violência em 1.333 escolas públicas estaduais do Rio Grande do Sul para o segundo semestre de 2016. Nesse período ocorreram 5225 casos de bullying, 6.314 casos de violência entre os alunos, 6870 de casos de violência contra os professores e 24.466 casos de indisciplina. Com os dados da CIPAVE ainda foi possível notar que, pelas 1.333 escolas estaduais da amostra, ocorreram 8,45 casos de bullying para cada 1.000 estudantes, 10,68 ocorrências de agressão física entre alunos, 11,62 casos de violência contra o professor e 41,41 ocorrências de indisciplina.

Gráfico 1 - Total de ocorrências na amostra das escolas estaduais do Rio Grande do Sul no segundo semestre de 2016

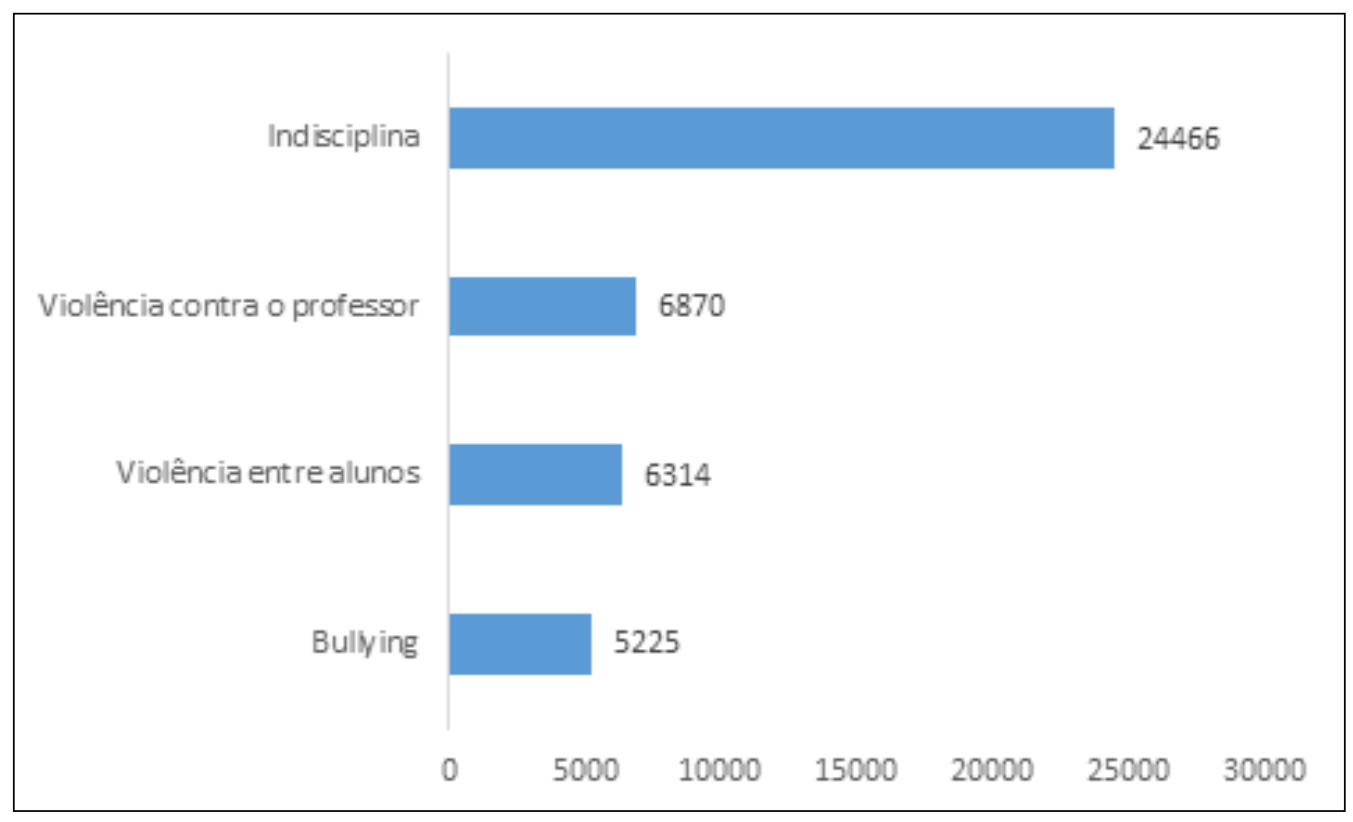

Fonte: elaboração própria. 
$\mathrm{Na}$ tabela a seguir são demonstrada as estatísticas descritivas das ocorrências de cada ato analisado, ${ }^{6}$ para cada 100 estudantes, tanto o valor bruto, quanto o corrigido pela taxa bayesiana. Como pode-se observar, a taxa bayesiana não interfere no valor médio das ocorrências, mas ela age suavizando os valores das escolas com poucos estudantes, por poder se tratar de um evento aleatório. Outro ponto importante da suavização, é que, além de fazer com que o valor da mediana se aproxime da média, ela diminui o desvio padrão e a diferença entre os valores máximos e mínimos.

Tabela 4 - Estatística descritiva dos dados

\begin{tabular}{l|l|l|l|l|l|l|l|l}
\hline & \multicolumn{4}{|c}{ Dados brutos } & \multicolumn{5}{c}{ Dados com o ajuste bayesiano } \\
\hline & OCB & OCVFA & OCI & OVP & OCBB & OCVFAB & OIB & OVPB \\
\hline Média & 1,04 & 1,32 & 4,80 & 1,46 & 1,04 & 1,32 & 4,80 & 1,46 \\
\hline Mediana & 0,36 & 0,48 & 1,78 & 0,58 & 0,84 & 1,27 & 4,64 & 1,31 \\
\hline Mínimo & 0,00 & 0,00 & 0,00 & 0,00 & 0,00 & 0,00 & 0,00 & 0,00 \\
\hline Máximo & 31,17 & 42,13 & 90,03 & 87,47 & 12,44 & 13,10 & 30,57 & 26,09 \\
\hline Desvio padrão & 2,28 & 2,64 & 8,85 & 3,79 & 0,86 & 0,89 & 3,11 & 1,14 \\
\hline
\end{tabular}

Fonte: elaboração própria.

\subsection{Resultados dos Indicadores de violência nas escolas estaduais do RS}

A tabela a seguir mostra as 20 escolas que ficaram com os maiores índices quanto a ocorrência de atos violência física entre os alunos. A escola com pior indicador teve como resultado o valor igual a um, e foi uma escola pertencente ao município de Lajeado. Logo após vem uma escola de Porto Alegre e uma escola de Viamão. Além disso, destaca-se nessa análise a relação de escolas pertencentes a municípios da Região Metropolitana de Porto Alegre (RMPA).

Ao olhar-se os resultados encontrados por Freitas, Cadaval e Gonçalves (2015), percebe-se que dentre os 30 municípios mais violentos do estado, tem-se esses mesmos municípios da RMPA presentes no ranking abaixo. Isso pode ser um indicativo que um município caracterizado pela violência reflita no comportamento agressivo dos alunos nas escolas. Corroborando com esse resultado têm-se escolas de municípios como Rio Grande, Cruz Alta, Passo Fundo, Santo Ângelo, e Venâncio Aires, que também são destaques como municípios violentos ${ }^{7}$.

\footnotetext{
6 Sendo: OCB a ocorrência de bullying; OCVFA refere-se a violência física entre os alunos; OCI são as ocorrências de indisciplina; OVP é a ocorrência de violência contra o professor. As ocorrências bayesianas de cada um desses atos são respectivamente: OCBB, OCVFAB, OIB, OVPB
}

7 Ver Freitas, Cadaval e Gonçalves (2015, p.13). 
Tabela 5 - Ranking das escolas com maior incidência de violência física entre alunos (IVFAB)

\begin{tabular}{l|l|l|l}
\hline Município & Alunos & Escola & IVFAB \\
\hline Lajeado & 375 & E.E.E.M. Santo Antônio & 1,00 \\
\hline Porto Alegre & 1.478 & E. E. E. M. Rafaela Remião & 0,67 \\
\hline Viamão & 385 & E. E. E. F. Canadá & 0,65 \\
\hline Santo Augusto & 303 & E.E.E.F. Francisco Andrighetto & 0,59 \\
\hline Trindade do Sul & 521 & E.E.E.M. Zenir Ghizzi da Silva & 0,56 \\
\hline Novo Hamburgo & 781 & E.E.E.F. João Ribeiro & 0,55 \\
\hline Santo Ângelo & 228 & E.E.E.F. Madre Catarina Lépori & 0,50 \\
\hline Cruz Alta & 1.066 & E.E.E.F. Dr. Gabriel A. de M. & 0,50 \\
\hline Novo Hamburgo & 410 & E.E.E.F. Ayrton S. do Brasil & 0,46 \\
\hline Montenegro & 102 & E.E.E.F.Aurélio Porto & 0,36 \\
\hline São Pedro do Sul & 283 & E.E.E.F. Professora H. Köetz & 0,36 \\
\hline Passo Fundo & 699 & E.E.E.M. General P. Guimarães & 0,36 \\
\hline Lajeado & 314 & E.E.E.F. Fernandes Vieira & 0,34 \\
\hline Seberi & 273 & E.E.E.F. Pedro Gemelli & 0,32 \\
\hline Montenegro & 681 & C.E. Ivo Bühler & 0,32 \\
\hline Cruzeiro do Sul & 478 & E.E.E.M. João de Deus & 0,31 \\
\hline Rio Grande & 113 & E.E.E.F. Alcides Barcelos & 0,30 \\
\hline Frederico Westphalen & 250 & E.E.E.F. Conselheiro E. M. de M. & 0,30 \\
\hline Sáo Francisco de Paula & 289 & E.E.E.M. Lajeado Grande & 0,29 \\
\hline Venâncio Aires & 543 & E.E.E.M. Crescer & 0,29 \\
\hline Fone &
\end{tabular}

Fonte: elaboração própria.

$\mathrm{Na}$ próxima tabela relacionam-se os resultados para as escolas com maior incidência de violência contra o professor, funcionário e diretor - são consideradas aqui as agressóes físicas e verbais. A escola de Lajeado que possuía maior incidência de violência entre alunos, também se destaca negativamente por ter o pior índice de violência contra o professor. Nota-se que esta escola possui apenas 375 estudantes, mas as ocorrências de violência no segundo semestre de 2016 na escola são as maiores da amostra. A segunda mais violenta nesse quesito pertence ao município de Ijuí, seguida de uma escola de Passo fundo. Nesse ranking, ainda, destaca-se a presença de mais uma escola de Passo Fundo, quatro escolas de Porto Alegre e duas de Santa Cruz do Sul. 
Tabela 6 - Ranking das escolas com maior incidência de violência contra o professor, funcionário e diretor (IVPB)

\begin{tabular}{l|l|l|l}
\hline Município & Alunos & Escola & IVPB \\
\hline Lajeado & 375 & E.E.E.M. Santo Antônio & 1,00 \\
\hline Ijuí & 290 & E.E.E.F.Ijuí & 0,46 \\
\hline Passo Fundo & 1.051 & E.E.E.M Protásio Alves & 0,37 \\
\hline Engenho Velho & 175 & E.E.E.M. Floriano Peixoto & 0,36 \\
\hline Porto Alegre & 871 & E.E.E.B. Monsenhor Leopoldo Hoff & 0,29 \\
\hline Santa Cruz do Sul & 863 & E.E.E.M. Willy Carlos Fröhlich & 0,24 \\
\hline Porto Alegre & 111 & E.E.E.F Camila Furtado Alves & 0,23 \\
\hline Erechim & 175 & E.E.E.F. Joaquim Pedro Salgado Filho & 0,23 \\
\hline Taquara & 778 & E.E.E.M. Willibaldo Bernardo Samrsla & 0,22 \\
\hline Novo Hamburgo & 410 & E.E.E.F. Ayrton Senna do Brasil & 0,21 \\
\hline Santa Maria & 625 & E.E.E.F Marieta D’Ambrosio & 0,21 \\
\hline Tenente Portela & 197 & E.E.I.F.Mukej & 0,21 \\
\hline Flores da Cunha & 207 & E.E.E.F. Professor Pedro Cecconello & 0,20 \\
\hline Passo Fundo & 699 & E.E.E.M. General Prestes Guimarães & 0,20 \\
\hline Frederico Westphalen & 250 & E.E.E.M Conselheiro E. M. de Mattos & 0,18 \\
\hline Santa Cruz do Sul & 1.078 & E.E.E.M. Alfredo José Kliemann & 0,17 \\
\hline Giruá & 597 & I.E.E. Joáo XXIII & 0,17 \\
\hline Porto Alegre & 1.229 & E.E.E.M.Mariz e Barros & 0,17 \\
\hline Porto Alegre & 215 & E.E.E.F. Professora M. M. de Souza & 0,16 \\
\hline Seberi & 273 & E.E.E.F. Pedro Gemelli & 0,16 \\
\hline Fonte & & \\
\hline & & & \\
\hline
\end{tabular}

Fonte: elaboração própria

A próxima tabela envolve a relação das escolas com mais ocorrências de bullying. $\mathrm{O}$ município de Porto Alegre é o principal destaque negativo, possuindo 5 escolas dentre os 20 piores índices de bullying, além de ter a escola pior colocada e que apresenta valor igual a 1. O município de Maquiné, que possui menos de 10 mil habitantes, e que náo está entre os municípios da RMPA, mas encontra-se dentro da mesorregiâo de Porto Alegre, também é destaque negativo, possuindo duas escolas no ranking, uma delas sendo a segunda com pior índice de bullying, 0,88. Outras escolas de municípios da RMPA destacam-se novamente no ranking, como escolas de Alvorada, Taquara, Viamão e Novo Hamburgo.

Tabela 7 - Ranking das escolas com maior incidência de bullying escolar (IBB)

\begin{tabular}{l|l|l|l}
\hline Município & Alunos & Escola & IBB \\
\hline Porto Alegre & 652 & E.E.E.F. Porto Alegre & 1,00 \\
\hline Maquiné & 592 & E.E.E.B. Lourenço Leon Von L. & 0,88 \\
\hline
\end{tabular}




\begin{tabular}{l|l|l|l}
\hline Município & Alunos & Escola & IBB \\
\hline Viamáo & 385 & E. E. E. F. Canadá & 0,77 \\
\hline Cruz Alta & 1.066 & E.E.E.F. Dr. Gabriel A. de Miranda & 0,75 \\
\hline Taquara & 778 & E.E.E.M. Willibaldo B. Samrsla & 0,65 \\
\hline Porto Alegre & 871 & E.E.EB Monsenhor L. Hoff & 0,59 \\
\hline Bom Princípio & 229 & E.E.E.F. Santa T. do Forromeco & 0,54 \\
\hline Alvorada & 688 & E.E. Minuano & 0,47 \\
\hline Ijuí & 556 & E.E.E.M. São Geraldo & 0,47 \\
\hline Porto Alegre & 1.478 & E. E. E. M. Rafaela Remião & 0,44 \\
\hline Erechim & 175 & E.E.E.F. Joaquim P. Salgado Filho & 0,41 \\
\hline Rio Pardo & 1.090 & I.E.E. Ernesto Alves & 0,37 \\
\hline Santo Ângelo & 1.027 & E.E.E.M. Dr. Augusto do N. e Silva & 0,37 \\
\hline Porto Alegre & 743 & E.E.E.M. Oscar Coelho de Souza & 0,36 \\
\hline Novo Hamburgo & 781 & E.E.E.F. Joáo Ribeiro & 0,31 \\
\hline Maquiné & 157 & E.E.E.M. Hilário Ribeiro & 0,31 \\
\hline Santa Rosa & 153 & E.E.E.F. Ermindo Vier & 0,29 \\
\hline Encantado & 127 & E.E.E.F. Érico Veríssimo & 0,27 \\
\hline Novo Hamburgo & 410 & E.E.E.F. Ayrton Senna do Brasil & 0,27 \\
\hline Porto Alegre & 1.229 & E.E.E.M.Mariz e Barros & 0,26 \\
\hline
\end{tabular}

Fonte: elaboração própria

Por fim, a próxima tabela apresenta o indicador de indisciplina das escolas estaduais do Rio Grande do Sul. A escola com pior índice de indisciplina pertence ao município de Santa Maria, tendo índice 1, seguido de uma escola de Farroupilha e outra de Novo Hamburgo, cujos índices foram 0,97 e 0,92, respectivamente. Como nos outros resultados, escolas que pertencem a RMPA são as que se destacam como as piores escolas nesse quesito.

Tabela 8 - Ranking das escolas com maior incidência de indisciplina entre alunos (IIB)

\begin{tabular}{l|l|l|l}
\hline Município & Alunos & Escola & IIB \\
\hline Santa Maria & 625 & E.E.E.F Marieta D’Ambrosio & 1,00 \\
\hline Farroupilha & 321 & C.E. Olga Ramos Brentano & 0,97 \\
\hline Novo Hamburgo & 410 & E.E.E.F. Ayrton Senna do Brasil & 0,92 \\
\hline Porto Alegre & 979 & C.E. Elpídio Ferreira Paes & 0,86 \\
\hline Porto Alegre & 678 & E.E.E.F. Lídia Moschetti & 0,86 \\
\hline Carazinho & 361 & I.E.E. Cruzeiro do Sul Oniva de Moura Brizola & 0,77 \\
\hline Cruz Alta & 1.066 & E.E.E.F. Dr. Gabriel Álvaro de Miranda & 0,77 \\
\hline Novo Hamburgo & 781 & E.E.E.F. João Ribeiro & 0,76 \\
\hline Caxias do Sul & 736 & E.E.E.M. Cavalheiro Aristides Germani & 0,71 \\
\hline
\end{tabular}




\begin{tabular}{l|l|l|l}
\hline Município & Alunos & Escola & IIB \\
\hline Lajeado & 375 & E.E.E.M. Santo Antônio & 0,70 \\
\hline Porto Alegre & 777 & E.E.E.F. Eva Carminatti & 0,69 \\
\hline Santo Augusto & 303 & E.E.E.F. Francisco Andrighetto & 0,66 \\
\hline Ijuí & 273 & E.E.E.F..Luiz Fogliatto & 0,64 \\
\hline Viamão & 385 & E. E. E. F. Canadá & 0,61 \\
\hline Alvorada & 1.636 & E.E.EM. Nossa Senhora Aparecida & 0,60 \\
\hline Porto Alegre & 770 & E.E.E.F. Vinte de Setembro & 0,54 \\
\hline Rosário do Sul & 317 & E.E.E.F. Professora Emília da Silva Prates & 0,54 \\
\hline Sáo Leopoldo & 474 & E.E.E.F. Dr. Mário Sperb & 0,52 \\
\hline Giruá & 597 & I.E.E. João XXIII & 0,51 \\
\hline Pelotas & 667 & C.E. Félix da Cunha & 0,49 \\
\hline
\end{tabular}

Fonte: elaboração própria

Os resultados dos quatro indicadores identificaram as escolas quanto a frequência das ocorrências, dando ênfase ao município em que a mesma está inserida. No entanto, é necessário frisar que por um município apresentar uma escola violenta dentro dos rankings acima, não o transforma no mais violento em âmbito escolar. Isso é contrastado com os dados do presente artigo, onde diversas escolas das regióes mais violentas do estado apresentaram zero ocorrências, para cada uma das tipologias. Isso é visto em Porto Alegre, por exemplo, que apresenta em muitos indicadores as escolas mais violentas, mas também possui muitas escolas onde não existe ocorrência de nenhum ato - o mesmo vale para os outros municípios analisados.

Em relação às escolas que obtiveram os melhores indicadores possíveis, ou seja, conseguiram zero ocorrências - dado bruto - para cada ato, na tabela seguinte pode-se ver que, no segundo semestre de 2016, em 425 escolas do Estado, não houveram casos de violência entre os alunos; em 403 não houveram ocorrências de violência contra os professores; em 506 não houveram casos de bullying; em 215 não houveram casos de indisciplina; e em 96 escolas não houveram nenhum dos quatro casos em conjunto.

Tabela 9 - Quantidade de escolas que obtiveram zero ocorrências

\begin{tabular}{l|c|c}
\hline Tipo de ocorrência & Quantidade de escolas & \% das 1333 escolas \\
\hline Violência entre os alunos & 425 & $32 \%$ \\
\hline Violência contra os professores & 403 & $30 \%$ \\
\hline Bullying & 506 & $38 \%$ \\
\hline Indisciplina & 215 & $16 \%$ \\
\hline Nenhuma das quatro ocorrências & 96 & $7 \%$ \\
\hline
\end{tabular}

Fonte: elaboração própria. 
Esse resultado acima pode ser explicado pelo fato de que algumas escolas, mesmo que inseridas em regióes violentas, conseguem minimizar a situação de violência, dado o ambiente em que a escola está inserida - nesse caso o município. Fica evidente que características do município podem de certa forma influenciar nas ocorrências de violência escolar, dado a localização da escola dentro do município - se está inserida em uma região menos violenta ou não -, bem como as próprias características da escola - infraestrutura, gestão, qualidade dos professores, entre outros.

Outra análise que foi realizada para os quatro tipos de ocorrências aqui medidos foi, a partir do critério das escolas com maior incidência de violência e indisciplina, detalhar qual foi o comportamento verificado nas demais escolas que pertencem ao mesmo município das escolas mais violentas. A ideia aqui é identificar quanto o fenômeno da violência e da indisciplina em uma escola pode ser derivado da característica do município como um todo.

Para facilitar a visualização dos resultados dos quatro indicadores utilizaram-se os intervalos de faixas criados na seção de métodos e dados deste artigo, ou seja, a primeira, entre zero e 0,1 , denominada como pouco frequente. A segunda, maior que 0,1 até 0,3 , considerada como frequente. A terceira, maior que 0,3 até 0,5 , definida como muito frequente. Por fim, a última faixa, extrema frequência, com valores maiores que 0,5 até 1 .

O gráfico a seguir mostra o resultado para a tipologia indisciplina para essa perspectiva. Estão representadas aqui 18 das 21 escolas com maior incidência de indisciplina. $\mathrm{O}$ que se pode notar, primeiramente, é que a maioria das escolas da amostra está presente no indicador de cor amarela, que representa casos de indisciplina frequente, tendo 991 escolas e média de 13 ocorrências por escola, no segundo semestre de 2016. Já no indicador de cor verde, que representa as escolas com zero ou pouca frequência de indisciplina, estão presentes 273 escolas com média de 7 ocorrências. As cores marrom e vermelha caracterizam, respectivamente, as escolas com muita e extrema frequência de casos de indisciplina. Em relação as escolas que apresentaram muita frequência, a média de ocorrências foi de 93 para o caso de 46 escolas, já o intervalo de extrema frequência apresentou média de 237 para 21 escolas. Pode-se notar que na maioria das cidades a escola mais indisciplinada não faz parte de um grupo de escolas com o mesmo grau deste ato.

$\mathrm{Na}$ maioria dos casos uma única escola estadual no município apresentou o grau mais elevado de indisciplina em relação a todo o Estado. Excetua-se aí a cidade de Novo Hamburgo, com duas escolas com muita violência em termos de indisciplina e Porto Alegre, com quatro escolas nesta faixa. No entanto, nota-se que existe, em proporção, um número menor de escolas no intervalo de zero ou pouca frequência de indisciplina, caracterizando um grande número de casos de indisciplina na maioria das escolas públicas do Rio Grande do Sul. 
Gráfico 2 - Escolas estaduais mais casos de indisciplina e o comportamento das demais escolas estaduais dentro do mesmo município

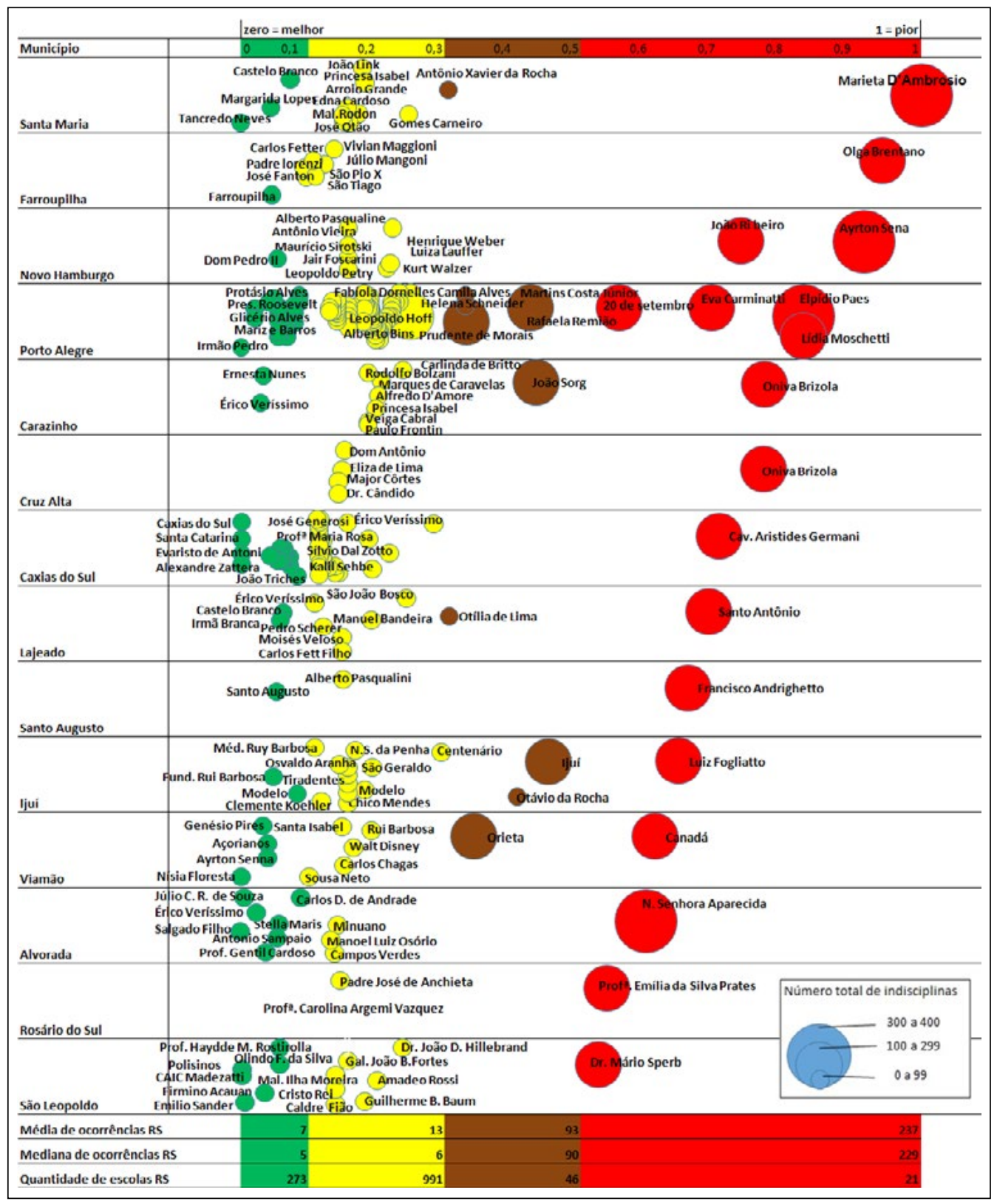

Fonte: elaboração própria

O gráfico abaixo apresenta a tipologia bullying nas escolas estaduais. A distribuição das ocorrências está mais concentrada nas faixas de zero ou pouca frequência. Em média são quase 109 ocorrências de bullying na faixa de extrema frequência, 49 na faixa de muito frequente, 5 na faixa de frequente e 2 no intervalo de pouco frequente. Conclui-se que há 
pouca ocorrência de bullying na maioria das escolas públicas do Rio Grande do Sul mas, principalmente, muitas escolas com zero ocorrências. No entanto, é necessário chamar a atenção para as escolas que apresentaram casos de bullying com extrema frequência, que apresentou média de aproximadamente 109 casos de bullying no segundo semestre de 2016.

Gráfico 3 - Escolas estaduais com maior nível de bullying e o comportamento das demais escolas estaduais dentro do mesmo município

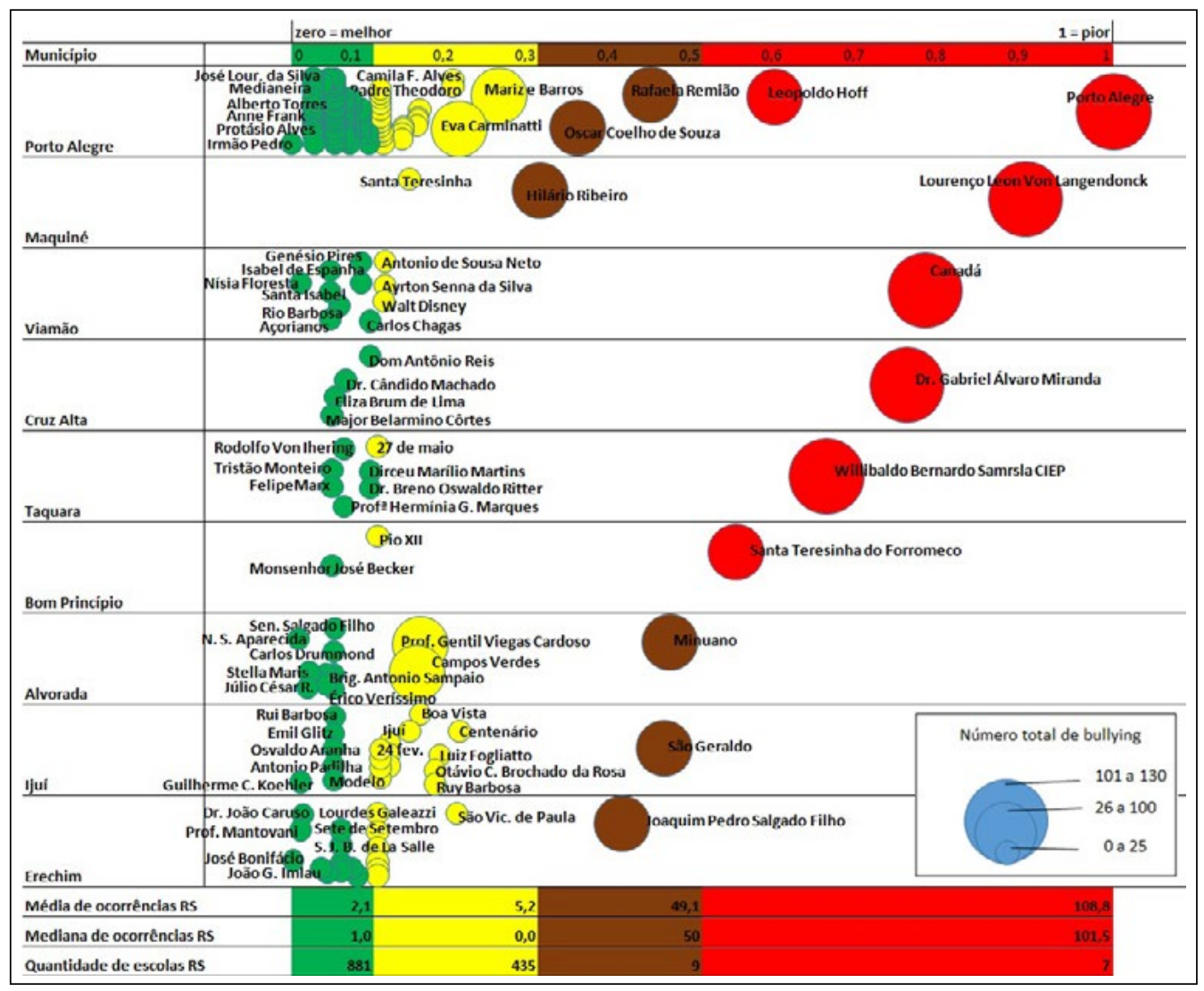

Fonte: elaboração própria

Agora, no gráfico 4, evidencia-se o nível de violência nas escolas estaduais no quesito de violência entre os alunos. O grau de concentração também é mais favorável aos menores índices do indicador. $\mathrm{O}$ número de ocorrências entre as escolas mais violentas é significativamente menor do que os verificados com a tipologia indisciplina e bullying. Inclusive, a média das duas classes mais violentas do indicador se mostram muito semelhantes e a mediana confirma o grau de heterogeneidade verificado dentro de cada uma destas classes. A mediana é maior que a média na classe de muita violência e, quase a metade da média na classe violência. 
Gráfico 4-Escolas estaduais com maior nível de violência entre os alunos e o comportamento das demais escolas estaduais dentro do mesmo município

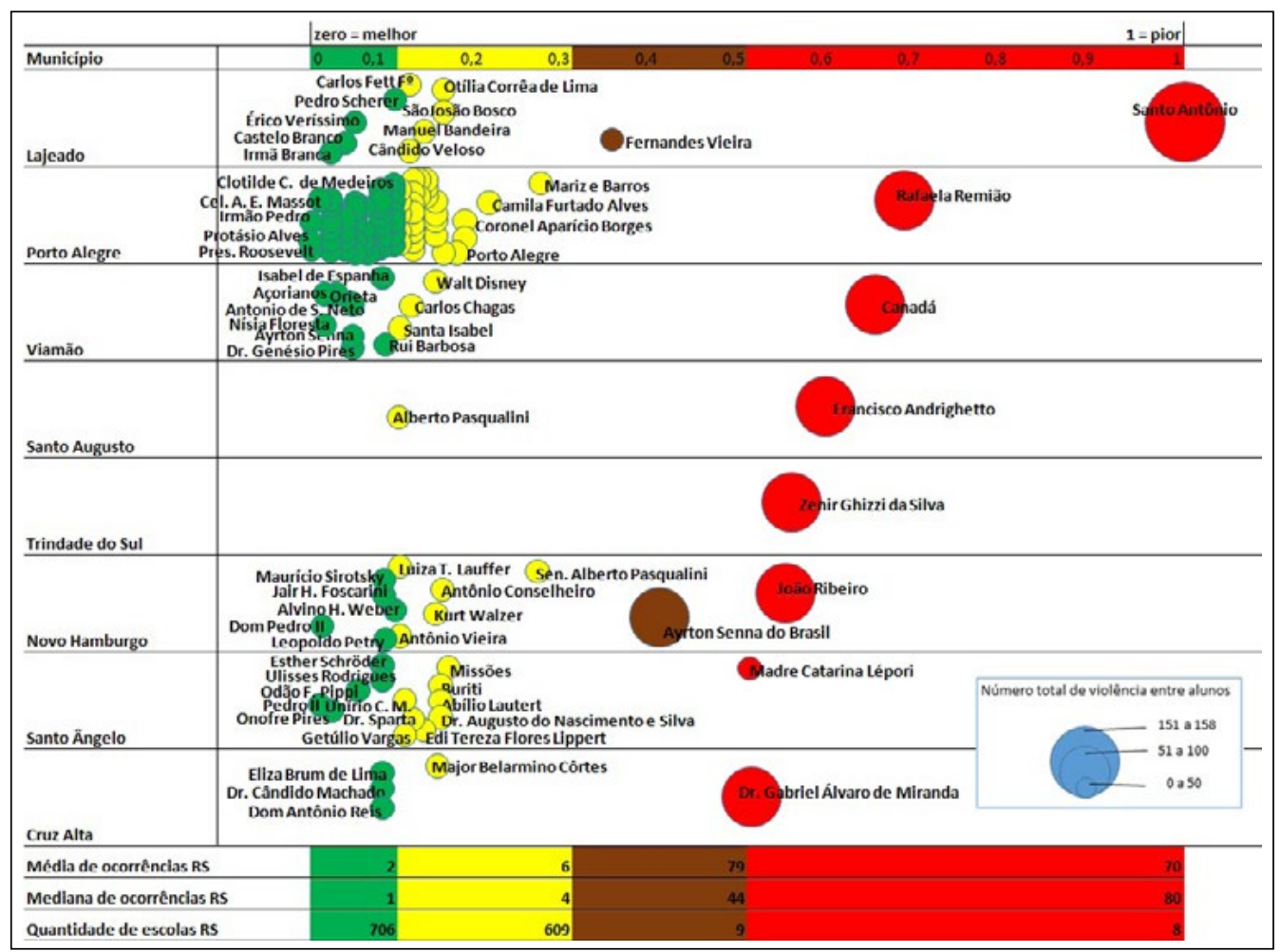

Fonte: elaboração própria.

Por fim, apresenta-se a quarta tipologia medida, o indicador de agressão aos professores, funcionários e diretores nas escolas estaduais. O gráfico mostra que a maior concentração das escolas está na faixa de zero ou pouca frequência desse ato, com um total de 1.263 escolas. Uma única escola ficou no intervalo extrema frequência e que fica localizada no município de Lajeado. A média e a mediana de ocorrências ficaram muito próximas nas faixas de extrema frequência, muito frequente, e frequente, com médias de 3 , 28 e 103 ocorrências, respectivamente. 
Gráfico 5-Escolas estaduais com maior nível de violência verbal aos professores, funcionários e diretores nas escolas estaduais e o comportamento das demais escolas estaduais dentro do mesmo município

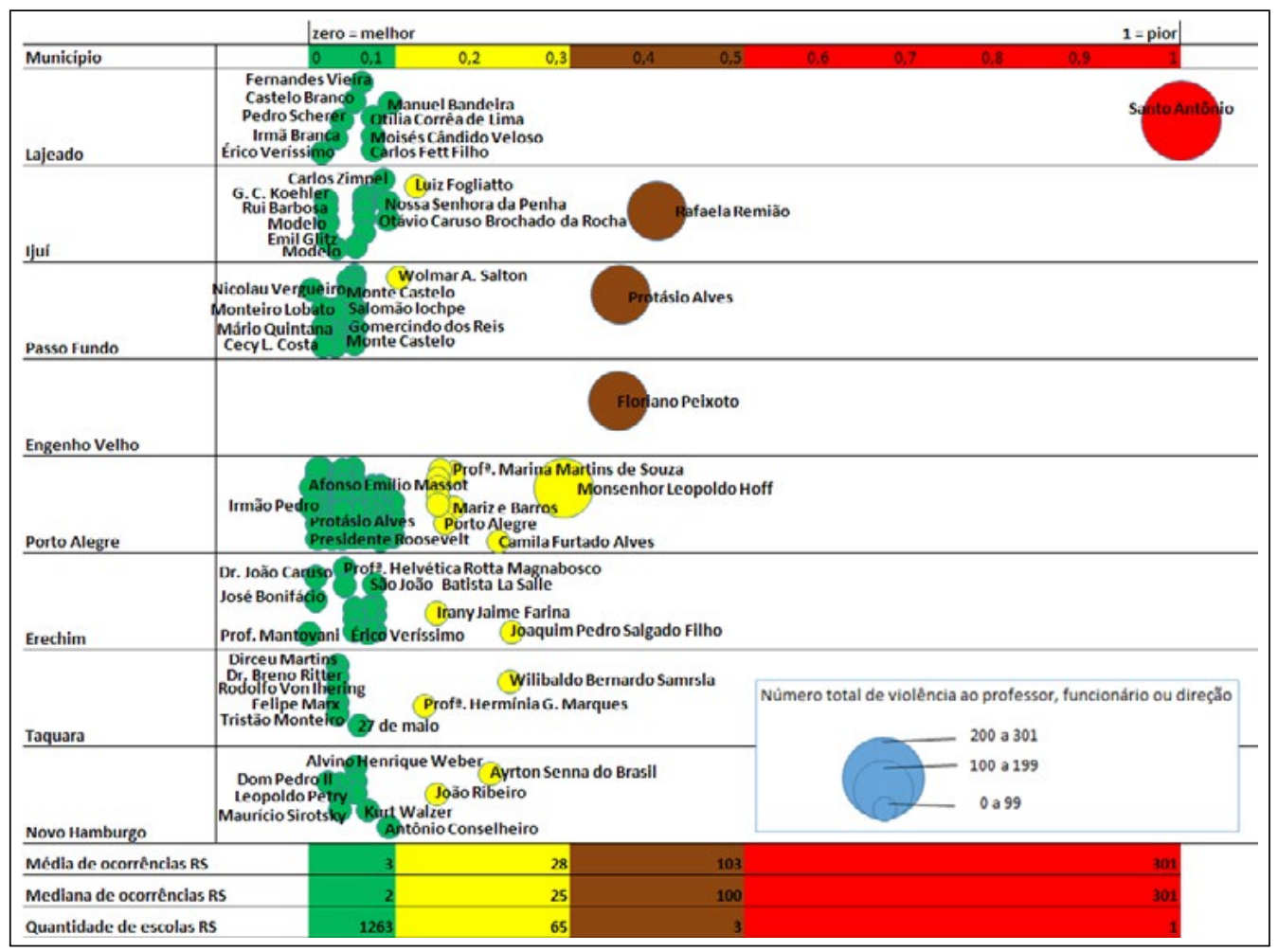

Fonte: elaboração própria.

\section{CONSIDERAÇÓES FINAIS}

O presente artigo visou analisar a indisciplina e a violência escolar nas escolas estaduais do Rio Grande do Sul por meio de 4 diferentes tipos de ocorrências escolares através de uma adaptação da metodologia derivada de Freitas, Cadaval e Gonçalves (2015).

De uma forma geral, as escolas piores colocadas nos rankings, são na maioria pertencentes à região metropolitana de Porto Alegre. Um fator que pode tentar justificar esse resultado é a violência urbana que os municípios dessa região presenciam. Isto pode influenciar comportamentos agressivos dos alunos dentro da escola. Como principal destaque negativo, destaca-se uma escola de Lajeado que possui o maior indicador de violência física entre os alunos e o maior de violência contra o professor, além de estar entre as dez piores escolas em relação à indisciplina.

Em um contexto combinando as quatro tipologias apresentadas, verifica-se que há um elevado nível de violência e indisciplina para um pequeno grupo de escolas estaduais no estado do Rio Grande do Sul e que, ainda que de forma pontual, não é raro ocorrer um 
elevado nível de violência em escolas pequenas e cidades pequenas. Destaca-se, por fim, que uma escola deve buscar como meta, zero ocorrências em termos das mais diversas tipologias. Açóes com vistas a alcançar esta meta devem ser constantemente empregadas no ambiente escolar, o que envolve os alunos, a sua família e os profissionais que atuam no ambiente escolar, sejam eles professores, funcionários próprios e terceirizados, administradores, prestadores de serviços, enfim, todos os envolvidos com o ambiente escolar.

É notável que, dentro da literatura econômica que trata de temas como o bullying, a violência contra o professor e a indisciplina, existem poucos trabalhos que abordem esse assunto empiricamente, principalmente tentando entender as causas da violência escolar, estando em mais evidência apenas os trabalhos que tratam da violência cometida por alunos contra outros alunos ou professores e funcionários da escola. Por esse motivo, o presente trabalho se justifica por servir como um primeiro sinal de identificação das escolas e das regióes mais indisciplinadas e violentas do estado. Como agenda para trabalhos futuros sugere-se utilizar o ranking gerado pelos indicadores de violência calculados neste artigo com outras informaçóes das escolas como infraestrutura, professores, alunos e, informaçóes do ambiente familiar dos alunos, além de informaçóes gerais dos municípios em que as escolas estáo localizadas.

Por fim, chama-se a atenção que a comissão da CIPAVE/RS além de fornecer a base de dados que gerou os quatro indicadores escolares neste artigo, como já foi citado, também passou a desenvolver açôes com vista a diminuir os resultados encontrados. É importante que medidas como esta, medição das ocorrências e açóes com vista a minimizálas, permaneçam e sejam ampliadas para todas as escolas estaduais.

\section{REFERÊNCIAS}

ABRAMOVAY M.; RUA M., Violências nas escolas, Vol. 1 of. 400 p., 2. ed., UNESCO, Brasília, 2002

AMMERMUELLER, A., Violence in european schools: victimization and consequences, Discussion Paper 07-004, Centre for European Economic Research ZEW, Mannheim. p. 1-40, 2007

BECKER, K. L.; KASSOUF, A. L.. Violência nas escolas públicas brasileiras: uma análise da relação entre o comportamento agressivo dos alunos e o ambiente escolar. Nova

Economia, v. 26, n. 2, 2016.

CARROL, B. (2006). The effects of school violence and crime on academic achievement, 33 p., Davidson College, 2006

COMISSÃO INTERNA DE PREVENÇÃO A ACIDENTES E VIOLÊNCIA ESCOLAR - CIPAVE . Disponível em: http://www.cipave.rs.gov.br/inicial. Acesso em: 03 de fevereiro de 2017 
FREITAS T. A. de; CADAVAL. A.; GONÇALVES. G.. A Estimação de um Índice Geral de Criminalidade para os Municípios do Rio Grande do Sul - IGcrime RS. IX Congresso Direito e Economia do IDERS 2015. Porto Alegre., 2015

GAMA, V., Uma análise de relação entre violência escolar e proficiência no município de Sáo Paulo, Mestrado em economia aplicada, Faculdade de Economia, Administração e Contabilidade de Ribeirão Preto, Universidade de São Paulo, Ribeirão Preto, 2009

GROGGER, Jeffrey. Local violence and educational attainment. Journal of human resources, p. 659-682, 1997.

HENRICH, C. C., SCHWAB-STONE, M., FANTI, K., JONES, S. M. e RUCHKIN, $\mathrm{V}$., 'The association of community violence exposure with middle-school achi-evement: a prospective study'. Journal of Applied Developmental Psychology 25(3), 327-348. Atlanta., 2004.

MARSHALL, R. J. Mapping disease and mortality rates using empirical bayes estimators. Journal of the Royal Statistical Society, v. 40, p. 2, p. 283-294, 1991.

MARTINS, A. M.; MACHADO, C.; FURLANETTO, E. C.. Mediação de conflitos em escolas: entre normas e percepções docentes. Cadernos de Pesquisa, v. 46, n. 161, p. 566592, 2016.

MATOS, Daniel Abud Seabra; FERRÃO, Maria Eugénia. Grade repetition and indiscipline: evidence from Brazil and Portugal in Pisa, 2012. Cadernos de Pesquisa, v. 46, n. 161, p. 614-636, 2016.

MCGARVEY, M., SMITH, W. J. e WALKER, M. B., The interdependence of school outcomes and school and neighborhood crime, Working Paper 07-19, Georgia State University, Department of Economics, Nebraska. 22 p, 2006.

OLIVEIRA, V. R.; FERREIRA, D. Violência e desempenho dos alunos nas escolas brasileiras: uma análise a partir do SAEB 2011. Anais do XVI Encontro de Economia da Região Sul, 2013.

OLWEUS, D.. Bullying at school and later criminality: Findings from three Swedish community samples of males. Criminal Behaviour and Mental Health, 21(2), 151-156, 2011.

PIQUERO, A. R., CONNELL, N. M., PIQUERO, N. L., FARRINGTON, D. P., e JENNINGS, W. G.. Does adolescent bullying distinguish between male offending trajectories in late middle age? Journal of Youth and Adolescence, 42, 444-453, 2013

RATNER, H. H., CHIODO, L., COVINGTON, C., SOKOL, R. J., AGER, J. e DELANEY-BLACK, V., 'Violence exposure, iq, academic performance, and chil-dren's 
perception of safety: evidence of protective effects', Merrill-Palmer Quarterly 52(2), 264-287, 2006

RENDA, J., VASSALLO, S., e EDWARDS, B.. Bullying in early adolescence and its association with anti-social behaviour, criminality and violence 6 and 10 years later.

Criminal Behaviour and Mental Health, 21(2), 117-127, 2011

ROCHA, K. de M. M. da et al. Violência na escola vivida por professores, funcionários e diretores. Northeast Network Nursing Journal, v. 13, n. 5, 2012.

SEVERNINI, E.; FIRPO, S. (2009). The relationship between school violence and student proficiency. Escola de Economia de São Paulo da Fundação Getulio Vargas (Texto para Discussão, 236). Disponível em: http://www.eesp.fgv.br/ Acesso em: 12 de janeiro de 2017.

SILVA, J. L. da et al. Associações entre bullying escolar e conduta infracional: revisão sistemática de estudos longitudinais. Psicologia: Teoria e Pesquisa, v. 32, n. 1, 2016.

SILVA, L. C. da; NOGUEIRA, M. A.. Indisciplina ou violência na escola. Uma distinção possível e necessária. In: GONÇALVES, L. A. O.; TOSTA, S. P. (Orgs.). A sindrome do medo contemporâneo e a violência escolar. Belo Horizonte: Autêntica, p. 15-62. 2008.

SPOSITO, M. P. A Instituição escolar e a violência. Cadernos de Pesquisa, São Paulo, v. 104 , p. 58-75, 1998.

TAVARES, P. A.; PIETROBOM, F. C. Fatores associados à violência escolar: evidências para o Estado de São Paulo. Estudos Econômicos (Sáo Paulo), v. 46, n. 2, p. 471-498, 2016.

TEIXEIRA, E. C.; KASSOUF, A. L.. Impacto da violência nas escolas paulistas sobre o desempenho acadêmico dos alunos. Economia Aplicada, v. 19, n. 2, p. 221-240, 2015. 